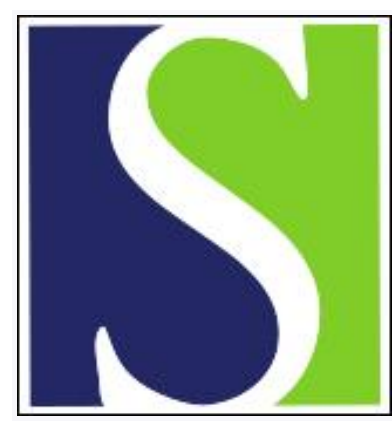

Scand J Work Environ Health 1990;16(2):129-134

https://doi.org/10.5271/sjweh.1807

Issue date: 01 Apr 1990

Symptoms of the neck and upper extremities in dentists.

by Milerad E, Ekenvall L

Affiliation: Department of Occupational Medicine, Karolinska Sjukhuset, Stockholm, Sweden.

This article in PubMed: www.ncbi.nlm.nih.gov/pubmed/2353196

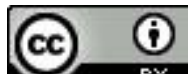




\title{
Symptoms of the neck and upper extremities in dentists
}

\author{
by Ewa Milerad, MD, Lena Ekenvall, MD ${ }^{1}$
}

\begin{abstract}
MILERAD E, EKENVALL L. Symptoms of the neck and upper extremities in dentists. Scand $J$ Work Environ Health 1990;16:129-34. Symptoms of the neck, shoulders, arms, and hands of 99 dentists and a reference group of 100 pharmacists were studied by means of a telephone interview. Forty-four percent of the dentists and $26 \%$ of the pharmacists reported symptoms of the neck [relative risk (RR) 2.1, $95 \%$ confidence interval $(95 \% \mathrm{CI}) 1.4-3.1$ ]. Symptoms of the shoulder were reported by $51 \%$ of the dentists and $23 \%$ of the pharmacists (RR $2.2,95 \%$ CI 1.5-3.3). Musculoskeletal symptoms in the forearm were present almost exclusively in the dentists $(12$ versus $1 \%)$. Numbness and paresthesia were more common among the dentists than among the referents (RR 4.2, $95 \%$ CI 2.3-7.7). Unilateral Raynaud's phenomenon in the dominant hand occurred in six dentists and one pharmacist. The high frequency of symptoms from the neck, shoulders, and upper extremities of the dentists was probably related to their difficult work positions with cervical flexion and rotation, abducted arms, and repetitive precision-demanding handgrips.
\end{abstract}

Key terms: musculoskeletal symptoms, neurological symptoms, Raynaud's phenomenon.

Dentistry work demands high precision and is often performed with the arms abducted and unsupported and the cervical spine flexed forward and rotated (1). A high static load is induced on the shoulder-neck region and shoulder joint by this posture (2). Static load of long duration may cause symptoms from the musculoskeletal system. Dentists have a high frequency of symptoms from the neck and shoulder regions (3). The prevalence of cervical spondylosis is higher among dentists than among farmers, and dentists also have a higher prevalence of glenohumeral joint osteoarthrosis than farmers (4). Lately, work with high-speed rotating handpieces and ultrasound equipment has been discussed in relation to reduced sensory perception (5) and Raynaud's phenomenon (6).

The objective of the present study was to describe and evaluate further the occurrence of musculoskeletal symptoms from the shoulder-neck region and upper extremities and to investigate whether or not Raynaud's phenomenon or neurological symptoms in the hands occur excessively among dentists. We also studied a reference group with the same methods to obtain appropriate relative risks.

\section{Subjects and methods}

\section{Subjects}

One hundred dentists in Stockholm were randomly selected from the dentist register in the Stockholm region. The criteria for inclusion were as follows: (i) year of birth 1932-1952, (ii) at least 10 years in clinical

\footnotetext{
Department of Occupational Medicine, Karolinska Sjukhuset, Stockholm, Sweden.
}

Reprint requests to: Dr E Milerad, Department of Occupational Medicine, Karolinska Sjukhuset, S-104 01 Stockholm, Sweden. practice after becoming qualified, and (iii) accessible via the dentist register or telephone directory of the Stockholm area.

One hundred pharmacists in the same age span as the dentists were selected from all the pharmacists in Stockholm. Pharmacists were chosen as referents since they have a physically light and varied work that cannot be expected to entail high static or dynamic load on the neck, shoulders, or arms. Moreover, the socioeconomic background of dentists and pharmacists is similar, and the two groups can be expected to have comparable medical knowledge.

The subjects were asked by letter if they were willing to participate in the study, and the study design was approved by the local ethics committee.

\section{Questionnaire}

The dentists and pharmacists were interviewed on the telephone by a physician according to a questionnaire. The questionnaire included questions on the work situation for the dentists only since pharmacists were chosen as referents because they have a physically varying and light work. The questionnaire was otherwise identical for both groups. The work-related questions concerned the years in clinical dentistry; workhours per day; minutes per day with high-speed drills, other drills, or ultrasound devices; and sitting or standing work position. General questions included handedness, vibration exposure during leisure time, smoking habits, and diseases other than musculoskeletal diseases. Symptom-related questions included symptoms of the neck, shoulders, upper arms, forearms, and hands at any time before the interview ("lifetime prevalence'). Neck and shoulder symptoms were further analyzed according to the Nordic questionnaire for the evaluation of musculoskeletal symptoms (7) as to duration during the last 12 months and during the last 
$7 \mathrm{~d}$, effect on work performance and leisure-time activities, and sick leave. Information on Raynaud's phenomenon was asked in such detail that the coldinduced symptoms could be graded according to the Taylor-Pelmear symptom scale (8). Neurological symptoms of the hands, such as numbness and paresthesia, were described as to location (median, ulnar or both nerves), and it was registered if the symptoms were radiating from the neck or only localized in the hands.

\section{Statistical analysis}

The ratio between the frequency of positive answers (yes to a symptom question) from the dentists and pharmacists was defined as the risk ratio (RR), which described the relation between the symptoms of the exposed dentists and those of the unexposed pharmacists. The risk ratio was calculated with the $95 \%$ confidence

Table 1. Sex distribution of, mean age of, and percentage of smokers among the dentists and pharmacists.

\begin{tabular}{|c|c|c|c|c|}
\hline \multirow[t]{2}{*}{ Group } & \multirow[t]{2}{*}{$\mathbf{N}$} & \multicolumn{2}{|c|}{$\begin{array}{c}\text { Age } \\
\text { (years) }\end{array}$} & \multirow{2}{*}{$\begin{array}{c}\text { Smokers } \\
(\%)\end{array}$} \\
\hline & & Mean & SD & \\
\hline Dentists & 99 & 46 & 5 & 21 \\
\hline $\begin{array}{l}\text { Men } \\
\text { Women }\end{array}$ & $\begin{array}{l}53 \\
46\end{array}$ & $\begin{array}{l}46 \\
47\end{array}$ & $\begin{array}{l}6 \\
5\end{array}$ & $\begin{array}{l}26 \\
15\end{array}$ \\
\hline Pharmacists & 100 & 46 & 5 & 17 \\
\hline $\begin{array}{l}\text { Men } \\
\text { Women }\end{array}$ & $\begin{array}{l}40 \\
60\end{array}$ & $\begin{array}{l}48 \\
46\end{array}$ & $\begin{array}{l}5 \\
6\end{array}$ & $\begin{array}{l}28 \\
10\end{array}$ \\
\hline
\end{tabular}

Table 2. Neck symptoms among the dentists and pharmacists with relative risk $(\mathrm{RR})$ and $95 \%$ confidence interval $(95 \% \mathrm{Cl})$.

\begin{tabular}{lcccc}
\hline Location of symptoms & $\begin{array}{c}\text { Den- } \\
\text { tists } \\
(\%)\end{array}$ & $\begin{array}{c}\text { Phar- } \\
\text { macists } \\
(\%)\end{array}$ & RR & $95 \% \mathrm{Cl}$ \\
\hline Neck & & & & \\
$\quad$ Men & 45 & 18 & 2.6 & $1.2-5.0$ \\
$\quad$ Women & 63 & 32 & 2.0 & $1.3-3.1$ \\
$\quad$ Men + women & 54 & 26 & 2.1 & $1.4-3.1$ \\
Neck and shoulder & 36 & 17 & 2.1 & $1.3-3.0$ \\
$\begin{array}{l}\text { Neck, shoulder and } \\
\text { upper arm }\end{array}$ & 16 & 3 & 5.4 & $1.6-17.9$ \\
\hline
\end{tabular}

interval $(95 \% \mathrm{CI})(9)$. When the frequency of symptoms was low, Fisher's exact test was used with a level of significance of $\mathrm{P}<0.05$.

\section{Results}

Ninety-nine of the 100 dentists and all of the pharmacists participated in the study. The age distribution was similar for both groups, as were smoking habits (table 1). Both groups had similar, low exposure to vibrating tools during leisure time. The frequency of diseases other than those of the musculoskeletal system was similar for the groups, and hypertension was the most common diagnosis, with six cases among the dentists and seven among the pharmacists. The mean employment time was 19 (SD 5.9) years for the dentists and 20.3 (SD 4.8) years for the pharmacists. The mean weekly worktime for the dentists was 40 (SD 7.2) h. Eighty-five dentists worked in a sitting position only, 11 reported both sitting and standing, and three used only the standing position. The employment time of both the dentists and pharmacists was correlated with age (correlation coefficient 0.84 and 0.89 , respectively).

\section{Neck}

The dentists had a higher frequency of cervical symptoms than the pharmacists (table 2). Among the female dentists the rate of symptoms increased with age (48 \% in the age group of 35-44 years and $73 \%$ in that of $45-55$ years). No such relation to age was observed among the female pharmacists or among the male dentists or pharmacists. The influence of employment time in dentistry on the symptoms could not be estimated, as it was strictly correlated with age.

The dentists with neck symptoms also had shoulder and arm symptoms more often than pharmacists with neck symptoms (table 2). Twenty-six dentists and 10 pharmacists with neck symptoms during the last 12 months had had symptoms more than $30 \mathrm{~d}$. Twentytwo dentists and 11 pharmacists were currently experiencing neck symptoms, and 14 and 4, respectively, had received medical treatment. Seven dentists but no pharmacist reported changing their work routines or reducing their workhours because of neck-shoulder

Table 3. Symptoms in the shoulders of the dentists and pharmacists with the relative risk (RR) and $95 \%$ confidence interval $(95 \% \mathrm{Cl})$.

\begin{tabular}{|c|c|c|c|c|}
\hline Location of symptoms & $\begin{array}{l}\text { Dentists } \\
(\%)\end{array}$ & $\begin{array}{l}\text { Pharmacists } \\
(\%)\end{array}$ & RR & $95 \% \mathrm{Cl}$ \\
\hline \multicolumn{5}{|l|}{ Shoulder } \\
\hline $\begin{array}{l}\text { Men } \\
\text { Women }\end{array}$ & $\begin{array}{l}36 \\
67\end{array}$ & $\begin{array}{l}15 \\
28\end{array}$ & $\begin{array}{l}2.4 \\
2.4\end{array}$ & $\begin{array}{l}1.0-5.4 \\
1.5-3.7\end{array}$ \\
\hline Men + women & 51 & 23 & 2.2 & $1.3-3.3$ \\
\hline $\begin{array}{l}\text { Shoulder without } \\
\text { concomitant neck symptoms }\end{array}$ & 15 & 4 & 3.8 & $1.2-10.3$ \\
\hline $\begin{array}{l}\text { Dominant side } \\
\text { Nondominant side } \\
\text { Both sides }\end{array}$ & $\begin{array}{l}7 \\
5 \\
3\end{array}$ & $\begin{array}{l}2 \\
2 \\
0\end{array}$ & $\begin{array}{l}3.5 \\
2.5\end{array}$ & $\begin{array}{l}\cdot \\
\cdot \\
\cdot\end{array}$ \\
\hline
\end{tabular}


Table 4. Symptoms in the forearms of the dentists and pharmacists with and those without concomitant neck-shoulder symptoms and the relative risk (RR) and $95 \%$ confidence interval $(95 \% \mathrm{Cl})$.

\begin{tabular}{|c|c|c|c|c|c|c|c|}
\hline \multirow[t]{2}{*}{ Forearm of occurrence } & \multicolumn{2}{|c|}{$\begin{array}{c}\text { Dentists }{ }^{a} \\
(\%)\end{array}$} & \multicolumn{2}{|c|}{$\begin{array}{c}\text { Pharmacists }^{a} \\
(\%)\end{array}$} & \multicolumn{2}{|c|}{$\mathrm{RR}^{\mathrm{a}}$} & \multirow[t]{2}{*}{$95 \% \mathrm{Cl}$} \\
\hline & With & Without & With & Without & With & Without & \\
\hline $\begin{array}{l}\text { Dominant side } \\
\text { Nondominant side } \\
\text { Both sides }\end{array}$ & $\begin{array}{l}7 \\
2 \\
1\end{array}$ & $\begin{array}{l}2 \\
0 \\
0\end{array}$ & $\begin{array}{l}0 \\
1 \\
0\end{array}$ & $\begin{array}{l}0 \\
0 \\
0\end{array}$ & $\dot{2}$ & $\dot{r}$ & $\dot{.}$ \\
\hline All combined & 10 & 2 & 1 & 0 & 12 & . & $2.3-24.1$ \\
\hline
\end{tabular}

a With = group with concomitant neck-shoulder symptoms, without = group without concomitant neck-shoulder symptoms

symptoms. Five dentists but no pharmacist had been on sick leave (two of them more than $30 \mathrm{~d}$ ) because of neck-shoulder symptoms during the 12 months preceding the interview. The female dentists reported neck symptoms 1.4 times more often than the male dentists $(95 \%$ CI $1.0-2.0)$, and corresponding symptoms were reported 1.8 times more often among the female than the male pharmacists $(95 \% \mathrm{CI} 0.8-3.9)$.

\section{Shoulders, upper arms, elbows}

Symptoms of the shoulders and the corresponding data from subjects with no concomitant neck problems are shown in table 3 . The shoulder on the dominant side was as often affected as that on the nondominant side. Four dentists and one pharmacist reported symptoms from the glenohumeral joint of the dominant side, and two dentists reported the same symptoms on the nondominant side. The upper arm and elbow symptoms were mainly localized in the dominant arm (12 of 14 dentists and 6 of 6 pharmacists). Eight dentists and four pharmacists reported elbow disorders. Lateral epicondylitis was the most commonly reported diagnosis for the arm with seven cases among the dentists (all on the dominant side) and four among pharmacists (three on the dominant side).

\section{Forearm}

Symptoms of the forearm are presented in table 4 . Eighty-three percent of the dentists with such symptoms also had neck and shoulder symptoms on the same side. The symptoms were generally localized in the dominant side $(75 \%)$. Only one pharmacist had forearm symptoms.

\section{Raynaud's phenomenon}

The prevalence of Raynaud's phenomenon among the dentists and pharmacists is shown in table 5 . In both groups the women reported a higher prevalence than the men. The male dentists had a higher frequency of Raynaud's phenomenon than the male pharmacists $(P<0.05)$. No such difference was observed for the women. A possible influence of smoking on Raynaud's phenomenon was not analyzed, since few subjects were smokers (table 1). Six dentists and one pharmacist had Raynaud's phenomenon localized exclusively in the
Table 5. Raynaud's phenomenon among the dentists and pharmacists with the relative risk (RR) and $95 \%$ confidence interval $(95 \% \mathrm{Cl})$.

\begin{tabular}{lrrrc}
\hline Side of occurrence & $\begin{array}{c}\text { Den- } \\
\text { tists } \\
(\%)\end{array}$ & $\begin{array}{c}\text { Phar- } \\
\text { macists } \\
(\%)\end{array}$ & RR & $95 \% \mathrm{Cl}$ \\
\hline Bilateral & 17 & 14 & 1.2 & $0.7-49.5$ \\
Dominant & 6 & 1 & 6.0 & $\cdot$ \\
Nondominant & 0 & 1 & 0.0 & $\cdot$ \\
All combined & 23 & 16 & 1.4 & $0.8-46.4$ \\
$\quad$ Men & 15 & 3 & 5.0 &. \\
$\quad$ Women & 33 & 25 & 1.3 & $\cdot$ \\
\hline
\end{tabular}

dominant hand $(\mathrm{P}=0.06)$. The majority of the subjects with Raynaud's phenomenon had grade II symptoms according to the Taylor-Pelmear symptom scale. More than half of the subjects with Raynaud's phenomenon also had neurological symptoms localized in the same hand or hands.

\section{Neurological symptoms}

The reported occurrence of neurological symptoms in the hands is shown in table 6 . The relative risks of the dentists compared with those of the pharmacists were high, especially for symptoms localized in the dominant hand only. Among the subjects with neurological symptoms in the hands, combined symptoms from the sensory distribution areas of the median and ulnar nerves were the most common in both the dentists and the pharmacists ( 27 versus 7 , respectively). Symptoms in the median area alone were more often reported by the dentists than the pharmacists, and these symptoms were mainly localized in the dominant hand. Nineteen dentists and four pharmacists had neurological symptoms without any relation to Raynaud's phenomenon or cervicobrachial symptoms (table 6). The distribution of the symptoms is shown in table 7 .

\section{Discussion}

In the present study the dentists reported symptoms of the neck and upper extremities more often than the pharmacists. The design of the study was cross-sectional, and a potential source of error thus was the "'healthy worker effect," ie, dentists who had given 
Table 6. Neurological symptoms among the dentists and pharmacists with and those without concomitant neck-shoulder symptoms or Raynaud's phenomenon on the same side and the relative risk (RR) and $95 \%$ confidence interval (95\% Cl).

\begin{tabular}{|c|c|c|c|c|c|c|c|c|}
\hline \multirow{2}{*}{ Hand of occurrence } & \multicolumn{2}{|c|}{$\begin{array}{c}\text { Dentists }{ }^{a} \\
(\%)\end{array}$} & \multicolumn{2}{|c|}{$\begin{array}{l}\text { Pharmacists }^{a} \\
(\%)\end{array}$} & \multicolumn{2}{|c|}{$\mathrm{RR}^{\mathrm{a}}$} & \multicolumn{2}{|c|}{$95 \% \mathrm{Cl}^{\mathrm{a}}$} \\
\hline & With & Without & With & Without & With & Without & With & Without \\
\hline Both hands & 19 & 4 & 8 & 1 & 2.4 & 4.0 & $1.1-5.2$ & . \\
\hline Dominant hand & 23 & 14 & 3 & 3 & 7.7 & 4.7 & $2.4-25.0$ & . \\
\hline Nondominant hand & 4 & 1 & 0 & 0 & $\cdot$ & $\cdot$ & $\cdot$ & $\cdot$ \\
\hline All combined & 46 & 19 & 11 & 4 & 4.2 & 4.8 & $2.3-7.7$ & $1.7-12.7$ \\
\hline $\begin{array}{l}\text { Men } \\
\text { Women }\end{array}$ & $\begin{array}{l}41 \\
52\end{array}$ & $\dot{ } \cdot$ & $\begin{array}{r}7 \\
13\end{array}$ & $\dot{.}$ & $\begin{array}{l}5.5 \\
3.9\end{array}$ & $\cdot$ & $\begin{array}{l}1.8-17.2 \\
1.9-7.9\end{array}$ & $\begin{array}{l}\cdots \\
\ldots\end{array}$ \\
\hline
\end{tabular}

a With = group with concomitant neck-shoulder symptoms or Raynaud's phenomenon on the same side, without = group without concomitant neck-shoulder symptoms or Raynaud's phenomenon on the same side.

Table 7. Neurological symptoms by nerve sensory distribution area among the dentists and pharmacists.

\begin{tabular}{|c|c|c|c|c|c|c|}
\hline \multirow{3}{*}{ Hand of occurrence } & \multicolumn{6}{|c|}{ Nerve } \\
\hline & \multicolumn{2}{|c|}{ Median } & \multicolumn{2}{|c|}{ Ulnar } & \multicolumn{2}{|c|}{ Median + ulnar } \\
\hline & Dentists & Pharmacists & Dentists & Pharmacists & Dentists & Pharmacists \\
\hline Dominant & 9 & 1 & 2 & 1 & 12 & 1 \\
\hline Nondominant & 1 & - & - & - & 4 & - \\
\hline Both & 6 & 1 & - & 1 & 11 & 6 \\
\hline
\end{tabular}

up clinical dentistry because of symptoms were not accessible for an interview. This possibility may have led to an underestimation of the relative risks. On the other hand, self-reported symptoms may be exaggerated in an exposed group and, therefore, lead to an overestimation of the relative risks. In the present study the interviewer knew if the subject was a dentist or a pharmacist, since work-related questions were included in the questionnaire. However, the interviews were performed according to a standardized format, and this standardization can be expected to minimize any influence of observer bias on the results.

Potentially confounding or modifying factors such as age, smoking habits, nonprofessional vibration exposure, and diseases other than those of the musculoskeletal system were similarly distributed in the dentist and reference groups. It is therefore not likely that these factors would explain our results, and the high occurrence of symptoms in the dentist group was probably related to differences in the work situation. However, we could not find any relation between symptoms and "exposure time" (eg, period of employment) among the dentists. Age and exposure time were closely related, but apart from the neck symptoms of the female dentists, there was no obvious connection between symptoms and age. The age group studied ( $35-55$ years) was limited and may have contributed to the lack of "age-response" or " dose-response" relationships.

The high frequency of neck complaints found among the dentists in this study was similar to that found in a previous study (3). The dentists also seemed to have more serious and long-term symptoms which influenced their work capacity and leisure-time activities. Neck symptoms were also more often combined with symptoms from the shoulders and arms among the dentists. The work posture with flexion and rotation of the cervical spine is a probable explanation for these symptoms. According to a previous study, dentists also have a high prevalence of cervical spondylosis (4), and even if the relation between cervical symptoms and radiographic cervical spondylosis is indistinct (10), both may be related to a high musculoskeletal load $(4,11)$.

Neck problems were more common among the female than the male dentists in the present study, although the relative risks in relation to female and male pharmacists were comparable. It is difficult to find comparable work situations for men and women with similar high musculoskeletal static components. To our knowledge, the present study is the first to demonstrate that the sexes seem equally prone to develop neck symptoms when subjected to equal work-related musculoskeletal strain.

In conformity with previous studies $(3,11)$, we found an increased risk for shoulder symptoms among the dentists. These symptoms were reported as often for the dominant as for the nondominant side, and this finding may reflect the work position with both arms abducted (1). At $30^{\circ}$ or more of abduction the perfusion of the supraspinatus tendon may decrease since the intramuscular pressure increases (12). The static contraction of a muscle in an abducted position may also cause impairment of the blood flow in the muscle (13). Decreased blood flow in the tendon of the supraspinatus muscle may cause degeneration of the 
tendon and rotator cuff tendinitis (14), which is a common cause of shoulder pain. In sit-down dentistry the work area is higher than elbow height. This situation may cause an elevation of the shoulder girdle. The static elevation of the shoulders may cause chronic myalgia in the descending part of the trapezius muscle, often referred to as tension neck syndrome (15).

Symptoms of the arms and elbows were also more common among the dentists than among the pharmacists. In contrast to shoulder symptoms, they were almost exclusively located on the dominant side. Dentists work with repetitive simultaneous power and precision-demanding grips without support for the arm. The high frequency of complaints from the arm and elbow may be due to a need for stabilization of the unsupported wrist.

The prevalence of Raynaud's phenomenon has been estimated to be about $5 \%$ for men (16) and $20 \%$ for younger women (17). Thus the prevalences found in our study were within the normal range for young women in pharmacy and for female dentists. The finding of an increased prevalence among male dentists only is difficult to explain, especially as the increase could not be attributed to unilateral symptoms. Unilateral Raynaud's phenomenon is unusual in the general population and can, according to the definition (18), not be defined as Raynaud's disease, but is presumed to be secondary to other diseases. The prevalence of symptoms exclusively localized in the dominant hand was high in the present study among the dentists, even if the difference between the dentists and the pharmacists was not significant. A similar tendency towards unilateral Raynaud's phenomenon in the dominant hand has previously been reported for male dentists (6). It is unknown whether or not high-frequency vibration can induce Raynaud's phenomenon, and the technical recommendations of the standard of the International Organization for Standardization only apply to frequencies between 5.6 and $1400 \mathrm{~Hz}$ (19), whereas the frequencies of high-speed equipment in dentistry are between 1000 and $40000 \mathrm{~Hz}$. Even if dentists have an increased prevalence of Raynaud's phenomenon, the explanation may be circulatory disturbances secondary to carpal tunnel syndrome or cervical nerve root compression (20) rather than highfrequency vibration. Occupational groups with repetitive hand movements have an increased frequency of carpal tunnel syndrome (21), and repetitive hand movements also characterize dentistry work. The symptoms may thus be secondary to other diseases possibly occurring more often in dentists than in pharmacists.

In this study neurological symptoms in the hands were common among the dentists. Only four referents had neurological symptoms not combined with Raynaud's phenomenon or neck-shoulder pain on the same side, whereas 19 dentists had such symptoms without any relation to radiating pain from the neck or Raynaud's phenomenon. The symptoms mainly occurred in the dominant hand or in both hands. The cause of neurological symptoms in the hands cannot be clarified in a telephone interview, but carpal tunnel syndrome is common in occupations with repetitive hand movements (21). In this study, the majority of neurological symptoms of the dentists were also localized in the area innervated by the median nerve. A peripheral nerve injury in the fingers cannot be excluded, however. Healthy dentists have a reduced perception for vibration in the dominant hand in comparison with that of the nondominant hand, and exposure to highspeed rotating handpieces has been discussed in relation to this finding (5). In addition, the extensive use of handtools in dentistry work can cause a chronic extrinsic compression of the nerves in the hand, and therefore may cause an entrapment of digital nerves (22). Whatever the cause of the symptoms, neurological disturbances are potentially serious in an occupation in which precise hand movements are necessary.

We conclude that dentists have a higher than expected risk for musculoskeletal symptoms in the neck and upper extremities. The probable reason for the high risk is their difficult work positions with the arms abducted and elevated, the cervical spine flexed and rotated, and repetitive precision-demanding handgrips. These work positions can be improved by preventive measures directed towards the workplace, eg, arm or hand support, appropriate construction of the dentist's chair, and appropriate design of the work unit. Another possible preventive approach is ergonomic education of the dentists and improvement of the work organization. The high occurrence of neurological symptoms in the hands is an observation that needs further evaluation. If the symptoms are due to peripheral nerve damage in the fingers as a result of exposure to high-frequency vibration, preventive measures are possible since these vibrations can easily be dampened. In contrast, if the symptoms are caused by nerve entrapment at the wrist or elsewhere, prevention may not be so simple.

\section{Acknowledgments}

This work was supported by a grant from the Swedish Work Environment Fund.

\section{References}

1. Green EJ, Brown ME. An aid to the elimination of tension and fatigue: body mechanics applied to the practice in dentistry. J Am Dent Assoc 1963;67:679-97.

2. Chaffin DB, Andersson GBJ. Occupational biomechanics. New York, NY: John Wiley \& Sons 1984;331 - 47.

3. Murtomaa $\mathbf{H}$. Work-related complaints of dentists and dental assistants. Int Arch Occup Environ Health 1982; $50: 231-6$.

4. Katevuo K, Aitasalo K, Lehtinen R, Pietilä J. Skeletal changes in dentists and farmers in Finland. Community Dent Oral Epidemiol 1985;13:23-5.

5. Lundström R, Lindmark A. Effects of local vibration on tactile perception in the hands of dentists. J Low Freq Noise Vib 1982;1:1-11. 
6. Dandanell R, Engström K. Vibrationsmiljön och skaderisker vid arbete med tandläkarborr med höga varvtal och ultraljudsverktyg [Vibration environment and risk for injuries from high-speed rotating handpieces and ultrasound equipment in dentistry work]. Stockholm: Swedish Work Environment Fund, 1984:735. (Arbetarskyddsfondens sammanfattningar.)

7. Kuorinka I, et al. Standardised Nordic questionnaires for the analysis of musculoskeletal symptoms. Appl Ergon 1987;18:233-7.

8. Taylor W, Pelmear PL, ed. Vibration white finger in industry. London: Academic Press 1975;xxi.

9. Rothman K. Modern epidemiology. Boston/Toronto: Little, Brown and Co, 1986:173.

10. Lawrence JS: Disc degeneration: its frequency and relation to symptoms. Ann Rheum Dis 1969;28:121-38.

11. Kajland A, Lindvall T, Nilsson T. Occupational medical aspects of the dental profession. Work Environ Health 1974;11:100.

12. Järvholm U, Palmerud G, Styf J, Herberts P, Kadefors R. Intramuscular pressure in the supraspinatus muscle. J Orthop Res 1988;6:230-8.

13. Järvholm U, Styf J, Suurkula M, Herberts $\mathbf{P}$. Intramuscular pressure and muscle blood flow in supraspinatus. Eur J Appl Physiol 1988;58:219-24.

14. Hagberg M, Hagberg C. Risks and prevention of musculoskeletal disorders among dentists. In: Brune D, Edling C, ed. Occupational hazards among health professionals. Boca Raton, FL: CRC Press Inc, 1989: $323-32$.
15. Hagberg M. Shoulder pain - pathogenesis. In: Hadler NM, ed. Clinical concepts in regional musculoskeletal illness. Orlando, FL: Grune \& Straton Inc, 1987:191200.

16. Chatterjee DS, Petrie A, Taylor W. Prevalence of vibration-induced white finger in fluorspar mines in Weardale. Br J Ind Med 1978;35: 208-18.

17. Olsen N, Nielsen LS. Prevalence of primary Raynaud phenomena in young females. Scand J Clin Lab Invest 1978;37:761-4.

18. Allen EV, Brown GE. Raynaud's disease: a critical review of minor requisites for diagnosis. Am J Med Sci 1932;183:187-200.

19. International Organization for Standardization. Guide for the measurement and the assessment of human exposure to vibration transmitted to the hand. Geneva: International Organization for Standardization 1985. (ISO 5349.)

20. Coffman JD, Davies WT. Vasospastic diseases: a review. Prog Cardiovasc Dis 1975;18:123-46.

21. Silverstein BA, Fine LJ, Armstrong TJ. Occupational factors and carpal tunnel syndrome. Am J Ind Med 1987;11:343-58.

22. Dawson DM, Hallett M, Millender LH. Digital nerve entrapment in the hand. In: Entrapment neuropathies. Boston/Toronto: Little, Brown and Company 1983 185-94.

Received for publication: 5 October 1989 